\title{
EFFECT OF FINE BUBBLES ON FLOW PROPERTIES IN BUBBLE COLUMN WITH SUSPENDED SOLID PARTICLES
}

\author{
ShigeHARU MOROOKA, TETSUya MIZOGUCHI, TOKIHIRo KAGO \\ AND YASUO KATO \\ Department of Applied Chemistry, Kyushu University, Fukuoka 812 \\ NóBUYUKI HIDAKA \\ Department of Chemical Engineering, Kagoshima University, Kagoshima 890
}

Key Words: Chemical Reactor, Energy, Coal, Coal Liquefaction, Dissolver, Bubble Column, Dispersion, Mixing, Particle, Gas Holdup

\begin{abstract}
Flow properties in a dissolver for direct coal liquefaction were simulated by using a cold bubble column of $12 \mathrm{~cm}$ i.d. To generate small gas bubbles in the column, a surfactant was added to tap water and a gas distributor with fine holes was employed. When glass spheres of 44 and $113 \mu \mathrm{m}$ dia. were suspended in the presence of the surfactant, the gas holdup was 1.5-4 times that for the tap water system, and the axial dispersion coefficient of liquid showed a minimum at superficial gas velocities of $3-5 \mathrm{~cm} \cdot \mathrm{s}^{-1}$. The mean settling velocity of solid particles, $v_{p}$, was affected by the quality of flow in addition to gas velocity and terminal velocity of solid particles. Most values of $v_{p}$ obtained in this experiment were larger than those for the tap water system where no fine gas bubbles were generated. Experimental equations for the correlation of $v_{p}$ are presented.

An introduction of secondary gas in the homogeneous bubble flow regime effectively increased the axial liquid mixing. This suggests that in the design of a dissolver quenching gas injection is important to attain spontaneous discharge of ash particles from the top of the vessel.
\end{abstract}

\section{Introduction}

In a dissolver for direct coal liquefaction, mineral matter such as $\mathrm{CaCO}_{3}, \mathrm{FeS}_{2}$ and $\mathrm{SiO}_{2}$ are likely to form agglomerates and accumulate at the reactor bottom. ${ }^{17)}$ If the axial liquid mixing is sufficiently large, however, these solid particles can be spontaneously discharged from the outlet at the top of the column even at low liquid velocities. ${ }^{10)}$ Thus the understanding of flow properties is an important factor in the design and operation of the dissolver.

The axial concentration distribution of solid particles in bubble columns has been investigated by many authors. ${ }^{3,5,7,15)}$ Kato et $a l^{5,7)}$ described the axial concentration distribution with a sedimentationdispersion model, and correlated the axial dispersion coefficients of liquid and solid particles and the mean settling velocity of solid particles.

Under the conditions of direct coal liquefaction, the gas holdup in the dissolver is much larger than that for air-water systems in the heterogeneous bubble flow and turbulent flow regime..$^{2,8,9,12,13,16)}$ The axial liquid mixing measured in dissolvers of $\mathrm{SRC}^{11,12)}$ and EDS $^{16)}$ processes is also quite different from that in

Received May I 1986. Correspondence concerning this article should be addressed to S. Morooka. T. Mizoguchi is now with Toyo Soda Mfg. Co., Ltd. Y. Kato is Professor Emeritus, Kyushu University. the air-water systems. ${ }^{6,7)}$ Therefore, the flow pattern in the dissolver at lower gas velocities seems to belong to the homogeneous bubble flow regime, where small gas bubbles with a narrow size distribution ascend at nearly the same rising velocities. However, the data of liquid mixing in dissolvers are not confirmed, and the characterization of homogeneous bubble flow is quite insufficient.

In this study, interfacial properties of water are changed by adding a surfactant and the characteristic flow in dissolvers is simulated in a cold flow model reactor. Gas holdup and axial liquid mixing in the homogeneous bubble flow regime are determined as functions of gas and liquid velocities. The effects of the presence of suspended solid particles and the interfacial property of liquid are also studied.

\section{Experimental}

Figure 1 shows the bubble column with suspended solid particles. The main column was $12 \mathrm{~cm}$ in i.d. and 205 or $226.5 \mathrm{~cm}$ high, and was made of an acrylic plastic pipe. Air was used as the gas phase and was introduced through two distributors. The primary gas distributor was a perforated plate $3 \mathrm{~mm}$ thick, having 85 holes of $1 \mathrm{~mm}$ dia. A bronze net of 65 mesh was put on the perforated plate to prevent the fall of solid particles. The mesh was partially clogged by solid 


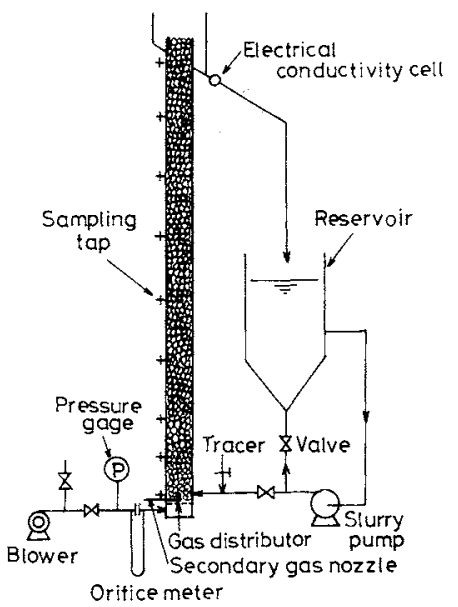

Fig. 1. Schematic diagram of experimental apparatus.

particles. The secondary gas distributor was a 3 or $6 \mathrm{~mm}$ i.d. single nozzle which was fixed $4 \mathrm{~cm}$ above the plate at the center of the cross section.

The liquid phase was tap water containing a surfactant (100 ppm of Trion X405; polyoxyethylene-piso-octylphenyl ether, Rohm \& Haas). Tap water without the additive was also used. The solid phase was sieved glass spheres (density $=2500 \mathrm{~kg} \cdot \mathrm{m}^{-3}$ ) with an average diameter of 44,113 and $230 \mu \mathrm{m}$.

After steady state was attained, the slurry was sampled from sampling taps on the wall. The solid concentration was obtained by weighing dried particles in each sample.

The axial dispersion coefficient of liquid was measured by the impulse response method. About $5 \mathrm{ml}$ of a $2 \mathrm{kmol} \cdot \mathrm{m}^{-3} \mathrm{KCl}$ solution was injected at the inlet and was detected by an electric conductivity cell at the outlet. The gas holdup was calculated from the gas volume in the column after the gas and liquid flows were interrupted simultaneously.

Table 1 shows the experimental conditions. The surface tension of water in the presence of the surfactant was $0.055 \mathrm{~N} \cdot \mathrm{m}^{-1}$. Experiments were carried out at temperatures between $287-303 \mathrm{~K}$.

\section{Experimental Results and Discussion}

\subsection{Gas holdup}

Figure 2 shows the relationship between gas holdup and superficial gas velocity. The data obtained in dissolvers of $\mathrm{EDS}^{16)} \mathrm{SRC}^{12)}$ and $\mathrm{IG}^{8)}$ processes are also shown in the figure. When the surfactant is added and solid particles of 44 or $113 \mu \mathrm{m}$ dia. are suspended in the range of $U_{g}<6 \mathrm{~cm} \cdot \mathrm{s}^{-1}$, small bubbles of about $2 \mathrm{~mm}$ dia. are produced without coalescence. As a result homogeneous bubble flow prevails in the bed. The gas holdup is 1.5-4 times larger than that for the tap water system without the addition of surfactant and is about the same as in actual dissolvers. The gas holdup increases with increasing gas velocity and
Table 1. Experimental conditions

\begin{tabular}{|c|c|c|c|c|}
\hline \multirow{2}{*}{$\begin{array}{c}d_{p} \\
{[\mu \mathrm{m}]}\end{array}$} & \multirow{2}{*}{$\begin{array}{c}\overline{\mathrm{C}} \\
{\left[\mathrm{Mg} \cdot \mathrm{m}^{-3}\right]}\end{array}$} & \multirow{2}{*}{$\begin{array}{c}U_{l} \\
{\left[\mathrm{~cm} \cdot \mathrm{s}^{-1}\right]}\end{array}$} & \multicolumn{2}{|c|}{ Key } \\
\hline & & & W & $\mathrm{T}$ \\
\hline 44 & & 0.2 & 0 & 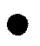 \\
\hline 44 & $0.05-0.1$ & 0.5 & (1) & 0 \\
\hline 44 & & 1.0 & $\ominus$ & $\odot$ \\
\hline 44 & 0.17 & 0.5 & $\phi$ & $\phi$ \\
\hline 113 & & 0.4 & $\square$ & $\mathbf{0}$ \\
\hline 113 & $0.05-0.1$ & 1.0 & III & $\square$ \\
\hline 230 & & 0.6 & $\triangle$ & $\Delta$ \\
\hline 230 & 00501 & 2.0 & $\nabla$ & $\nabla$ \\
\hline 230 & $0.05-0.1$ & 3.0 & $\Delta$ & \\
\hline 230 & & 4.0 & $\triangle$ & $\Delta$ \\
\hline
\end{tabular}

$\mathrm{W}$, tap water; $\mathrm{T}, 100 \mathrm{ppm}$ Triton $\mathrm{X}-405$ solution.

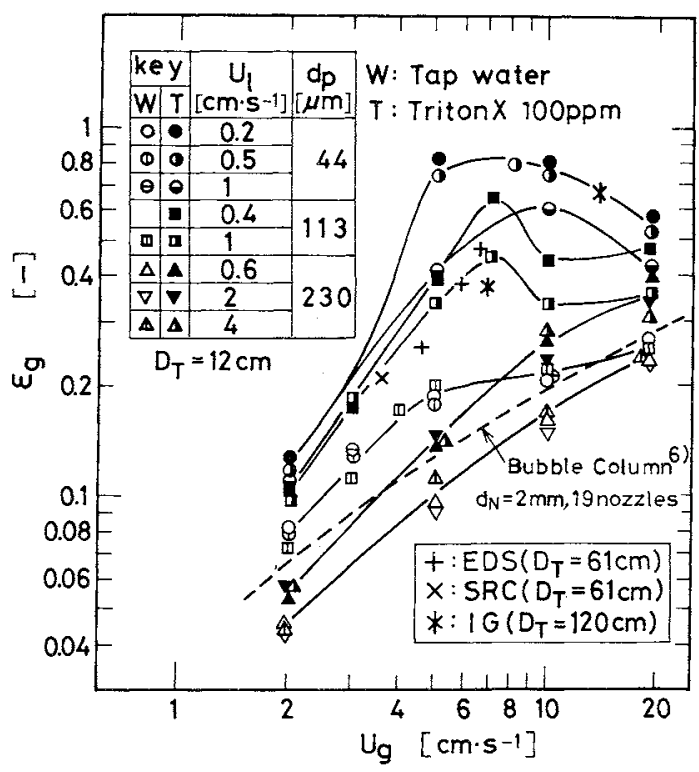

Fig. 2. Effect of gas velocity on gas holdup.

decreases with increasing liquid velocity.

In the range of $U_{g}>6 \mathrm{~cm} \cdot \mathrm{s}^{-1}$, gas bubbles in the surfactant-containing water begin to coalesce. The gas holdup decreases with increasing gas velocity, and the flow regime changes to heterogeneous bubble flow and then to turbulent flow.

When solid particles of $230 \mu \mathrm{m}$ dia. are suspended, coalescence of bubbles occurs in spite of the addition of the surfactant. The gas holdup is $1.2-1.5$ times larger than that for the tap water system without the addition of surfactant. The effect of superficial liquid velocity on gas holdup for $d_{p}=230 \mu \mathrm{m}$ is negligible in the range of $U_{l}<4 \mathrm{~cm} \cdot \mathrm{s}^{-1}$.

\subsection{Liquid mixing}

Figure 3 shows the longitudinal dispersion coefficient of liquid in the bubble column with suspended solid particles, $E_{s l}$. With increasing gas velocity, $E_{s l}$ in the presence of the surfactant first decreases, passes 


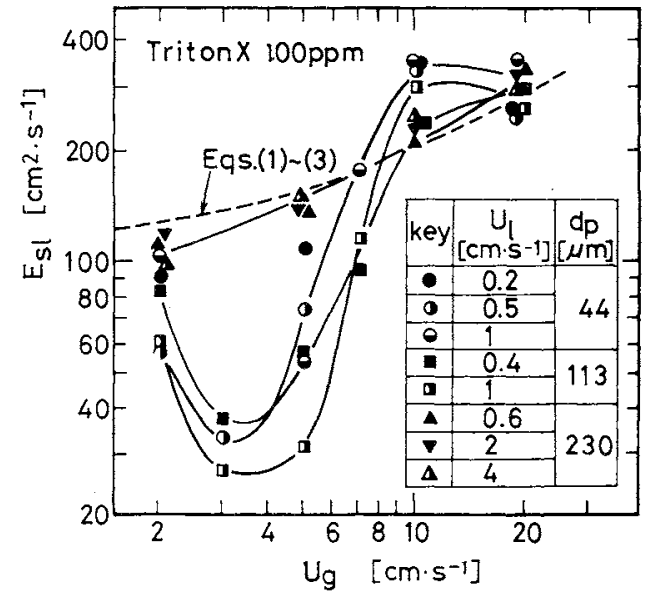

Fig. 3. Effect of gas velocity on $E_{s l}$.

the minimum value and then increases.

Kato and Nishiwaki ${ }^{6}$ correlated the axial dispersion coefficient of liquid for the air-water system in the heterogeneous bubble flow and turbulent bubble flow regime by the following equations.

$$
\begin{gathered}
\frac{\left(U_{g} D_{T} / E_{l}\right)}{\left(\varepsilon_{g}^{*} / \varepsilon_{g}\right)^{\alpha}}=\frac{13\left(U_{g} / \sqrt{g D_{T}}\right)}{1+6.5\left(U_{g} / \sqrt{g D_{T}}\right)^{0.8}} \\
\varepsilon_{g}^{*}=\frac{U_{g}}{31+4.5 U_{g}^{0.8}\left\{1-\exp \left(-0.040 U_{g}^{1.8}\right)\right\}} \\
\alpha=1-\exp \left(-0.2 U_{g}^{2}\right)
\end{gathered}
$$

where the superficial gas velocity, $U_{g}$, is expressed in the unit of $\mathrm{cm} \cdot \mathrm{s}^{-1}$. The broken line in Fig. 3 shows the values calculated from Eqs. (1)-(3). In the range of $U_{g}=3-5 \mathrm{~cm} \cdot \mathrm{s}^{-1}$, the experimental values of $E_{s l}$ in the presence of the surfactant are 1/2-1/5 those of Kato and Nishiwaki. $\left.{ }^{6}\right)$ When the solid particles of $230 \mu \mathrm{m}$ are suspended in the presence of the surfactant, however, the value of $E_{s l}$ is nearly in agreement with Eqs. (1)-(3). This means that the presence of coarser solid particles causes the coalescence of gas bubbles.

Figure 4 shows the correlation of $E_{\mathrm{sl}}$. The definitions of the coordinates are identical with that of Kato et al. ${ }^{6)}$ The experimental values of $E_{s l}$ in the homogeneous bubble flow regime can be expressed by the solid line, while those for the tap water system are well expressed by Eqs. (1)-(3).

Figure 5 shows the correlation of $E_{s l}$ obtained in dissolvers for direct coal liquefaction. These data are in agreement with the solid line, which expresses the correlation of $E_{s l}$ in the presence of the surfactant. The values of $E_{l}$ obtained by Aoyama et al. ${ }^{13}$ and $\mathrm{Kato}^{4)}$ show the same tendency as the solid line. However, the axial dispersion coefficient of liquid in the presence of the surfactant is strongly dependent on liquid properties and gas distributor type. Schügerl

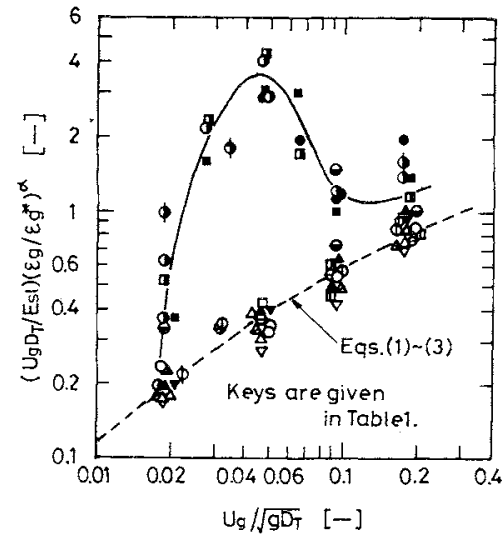

Fig. 4. Correlation of $E_{\mathrm{s} !}$.

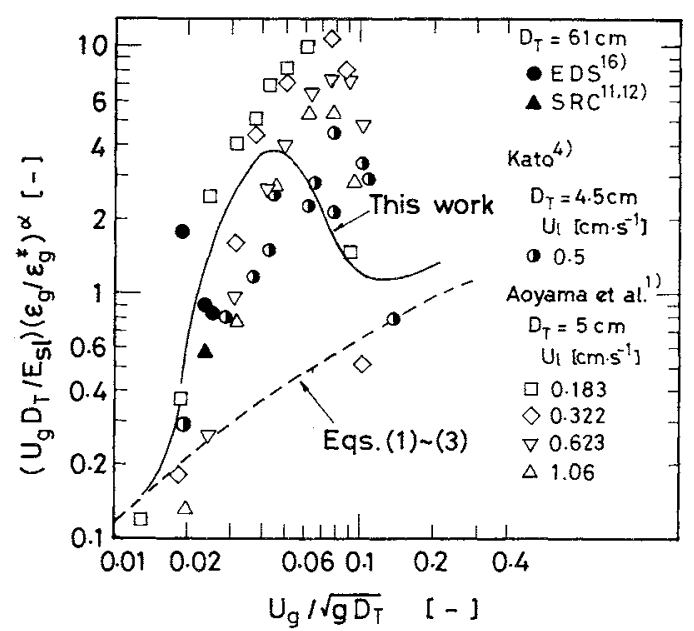

Fig. 5. Correlation of $E_{s l}$ and $E_{l}$ in literature.

et al. ${ }^{14)}$ also reported the complex effects of additives and gas distributors.

\subsection{Secondary gas}

The secondary gas which is introduced through a single nozzle produces large bubbles. These bubbles ascend along the central axis of the column, inducing an upward flow in the central region and a downward flow in the peripheral region.

Figure 6 shows the effect of the secondary gas velocity on the gas holdup and the axial dispersion coefficient of liquid. The total superficial gas velocity, $\left(U_{g}+U_{g s}\right)$, is fixed at 3 and $4 \mathrm{~cm} \cdot \mathrm{s}^{-1}$. The gas holdup decreases with increasing secondary gas velocity. The value of $E_{s l}$ increases with increasing secondary gas velocity and becomes equivalent to that of the heterogeneous bubble flow when $U_{g s}$ exceeds about $0.5 \mathrm{~cm} \cdot \mathrm{s}^{-1}$. This means that the axial liquid mixing is much affected by internal recirculation flow, which is easily induced by a small amount of coalesced bubbles. In this sense, the solid line in Fig. 4 indicates a typical correlation of $E_{s l}$ in the homogeneous bubble flow regime. The value of $E_{s l}$ under other circumstances varies between the solid and broken lines in Fig. 4. 


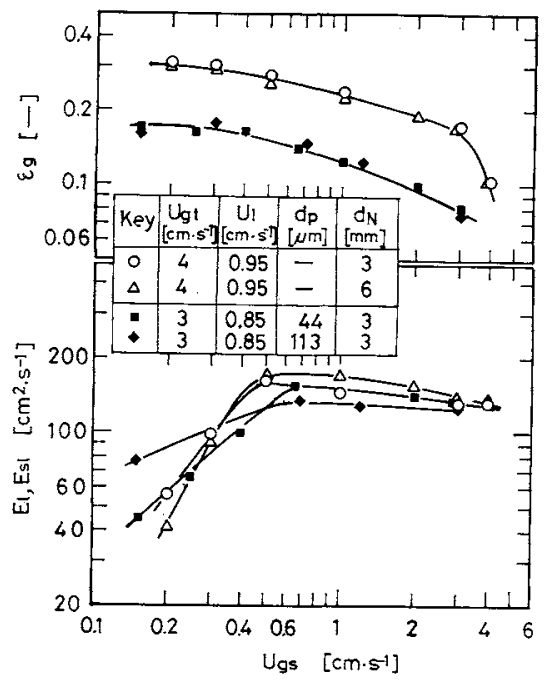

Fig. 6. Effect of secondary gas flow on gas holdup and liquid mixing.

\subsection{Axial concentration distribution of solid particles}

If the concentration of solid particles is low, the settling velocity of solid particles. $v_{p}$, is not affected by the local solid concentration, $C$, which is then expressed as follows: ${ }^{5,7)}$

$$
\begin{aligned}
C & =\left(C_{0}+\frac{u_{l}}{v_{p}-u_{l}} C^{*}\right) \exp \left\{\frac{-\left(v_{p}-u_{l}\right)}{E_{p}} z\right\}-\frac{u_{l}}{v_{p}-u_{l}} C^{*} \\
& =\left(C_{L}+\frac{u_{l}}{v_{p}-u_{l}} C^{*}\right) \exp \left\{\frac{v_{p}-u_{l}}{E_{p}}(L-z)\right\}-\frac{u_{l}}{v_{p}-u_{l}} C^{*}
\end{aligned}
$$

where $C_{0}$ and $C_{L}$ are the solid concentration extrapolated to $z=0$ and $z=L$, respectively. $C^{*}$ is the solid concentration in the feed.

Figure 7 shows examples of the axial concentration distribution of solid particles. The axial concentration gradient in the presence of the surfactant is generally larger than that for the tap water system and becomes maximum at $U_{g}=3-5 \mathrm{~cm} \cdot \mathrm{s}^{-1}$. Figure 8 also illustrates how the secondary gas improves the axial concentration distribution of solid particles in the column.

\subsection{Mean settling velocity of solid particles}

When solid particles of $230 \mu \mathrm{m}$ were suspended, $\varepsilon_{q}$ and $E_{s l}$ were not affected by the liquid velocity, as shown in Figs. 2 and 3. Then $E_{p}$ and $v_{p}$ were calculated separately from Eq. (4) by using the linear relationship between $\left(v_{p}-u_{l}\right) / E_{p}$ and $u_{l}$. The value of $E_{p}$ obtained in this way was in agreement with $E_{s l}$ as determined by the impulse response method. Solid particles smaller than $230 \mu \mathrm{m}$ are supposed to behave more like liquid phase. ${ }^{5)}$ Therefore, the axial dispersion coefficient of solid particles can be approximated by that of liquid in the range of the present experiment. With this assumption, $v_{p}$ is the only unknown parameter in Eq. (4) and is obtained by comparing an experimental concentration distribution of solid par-

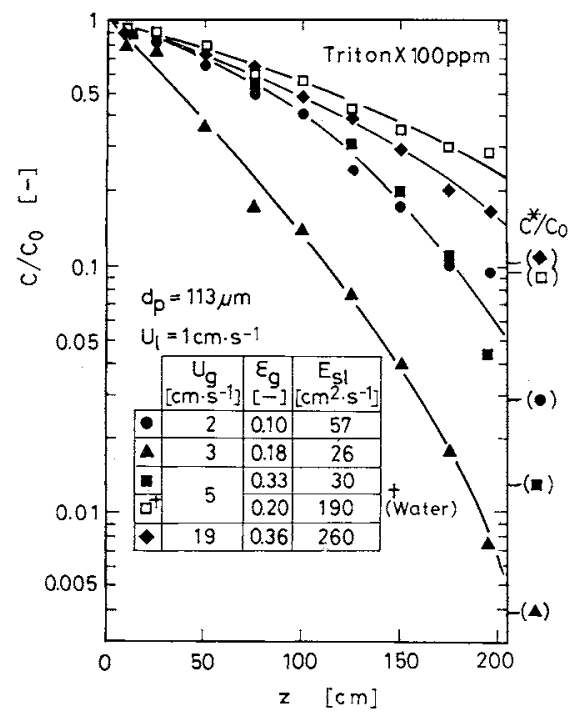

Fig. 7. Axial concentration distributions of solid particles.

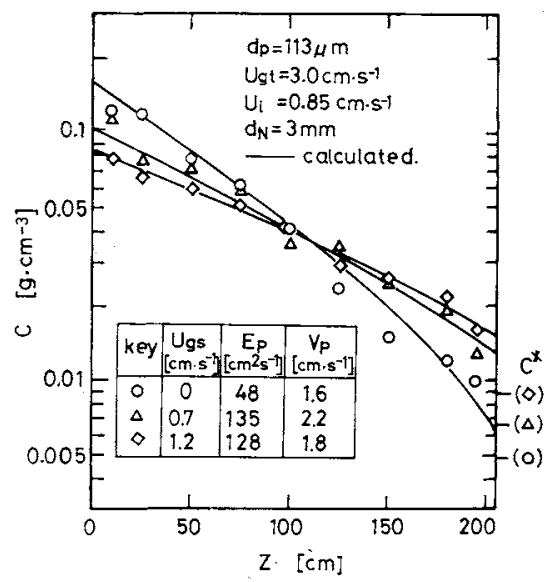

Fig. 8. Effect of secondary gas flow on axial concentration distribution of solid particles.

ticles with Eq. (4).

Figure 9 shows the mean settling velocity normalized with the terminal velocity of a solid particle on the basis of the correlation of Kato et al. ${ }^{5,7)}$ The solid lines indicate $v_{p}$ in the presence of the surfactant, while the chain line shows that for the tap water system. The broken line is the correlation of Kato et $a l .{ }^{5)}$ in the heterogeneous flow and turbulent flow regime and is calculated from

$$
v_{p}=v_{t}\left\{1+1.5\left(U_{g} / v_{t}\right)\right\}^{0.30} \psi_{l}^{2.5}
$$

Most of the values obtained in this experiment are larger than those from Eq. (5). Especially, the mean settling velocity in the presence of the surfactant deviates nonlinearly from Eq. (5) and is strongly affected by the quality of flow as well as the terminal velocity of solid particles and superficial gas velocity. The quality of flow is dependent on type of gas distributor, properties of the liquid, column size and gas and liquid velocities. 


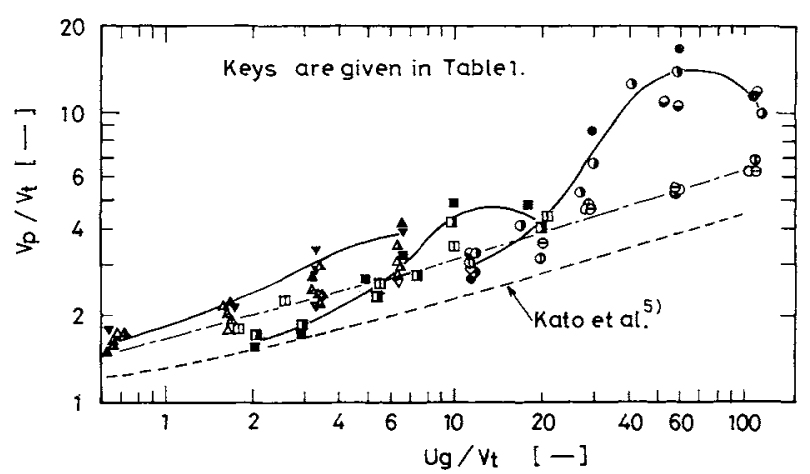

Fig. 9. Relationship between $v_{p} / v_{l}$ and $U_{g} / v_{t}$.

Figure 10 shows the effects of particle diameter and gas holdup on $\left(v_{p}-v_{t}\right) / v_{t}$. The value of $\left(v_{p}-v_{t}\right) / v_{t}$ increases with increasing gas holdup and with decreasing mean particle diameter.

Figure 11 shows the correlation of $v_{p}$ in the homogeneous bubble flow regime, and the following experimental equation is obtained.

$$
v_{p} / v_{t}=1+3.5 \varepsilon_{g}\left(d_{p} v_{t} / v_{l}\right)^{-0.55}
$$

where the gas holdup is a function of superficial gas velocity and other factors and can be estimated from Fig. 2.

Figure 12 is the correlation of $v_{p}$ in the heterogeneous bubble flow and turbulent flow regime. The solid line in Fig. 12 is expressed by the following equation.

$$
v_{p} / v_{t}=1+10 \varepsilon_{g}\left(d_{p} v_{t} / v_{l}\right)^{-0.25}
$$

Values obtained by Kato et al. ${ }^{7)}$ and Smith and Ruether ${ }^{15)}$ are roughly in agreement with Eq. (7).

\section{Conclusion}

Flow characteristics in dissolvers for direct coal liquefaction processes were simulated in a cold flow model reactor by producing small gas bubbles in the presence of a nonionic surfactant.

The gas holdup decreased with increasing particle diameter. With solid particles of 44 or $113 \mu \mathrm{m}$ dia., the gas holdup decreased with increasing liquid velocity.

The longitudinal dispersion coefficient of liquid in the presence of a surfactant was $1 / 5-3 / 2$ that for the tap water system, and showed a minimum in the range of $U_{g}=3-5 \mathrm{~cm} \cdot \mathrm{s}^{-1}$. When solid particles of $230 \mu \mathrm{m} \mathrm{dia}$. were suspended, however, the liquid mixing was approximately in agreement with that for the tap water system.

The introduction of secondary gas in the homogeneous bubble flow regime effectively increased the axial mixing of liquid and solid. This indicates that the design of quenching gas injection in a dissolver plays an important role in avoiding the accumulation of ash particles at the dissolver bottom.

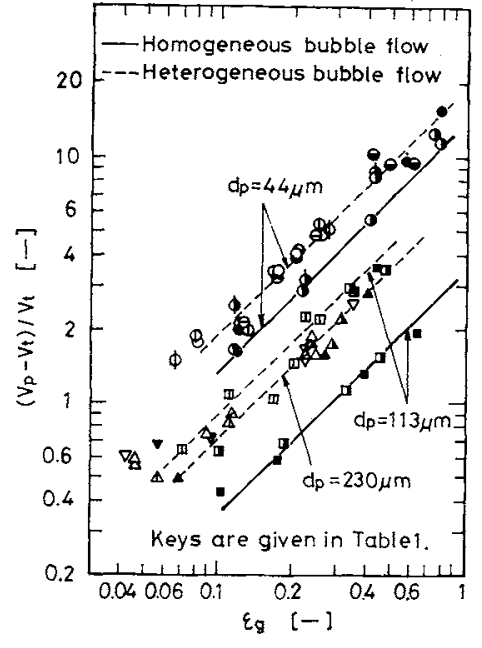

Fig. 10. Effects of particle diameter and gas holdup on $v_{p}$.

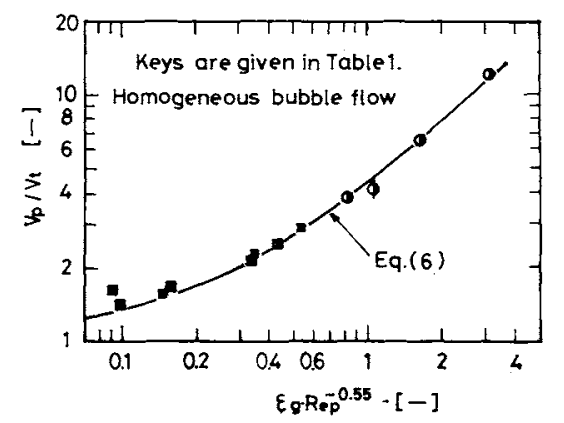

Fig. 11. Correlation of $v_{p}$ in homogeneous bubble flow regime.

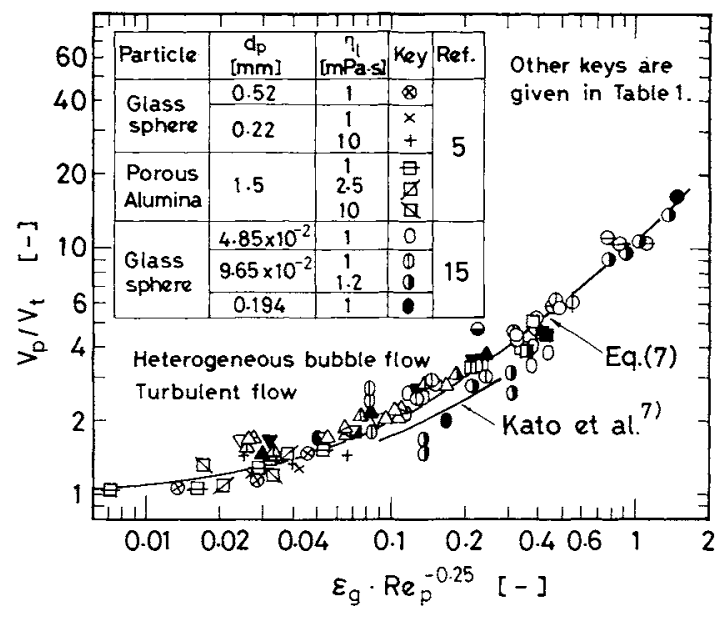

Fig. 12. Correlation of $v_{p}$ in heterogeneous bubble flow and turbulent flow regime.

The mean settling velocity of solid particles in the homogeneous bubble flow regime was correlated by Eq. (6). The value of $v_{p}$ in the heterogeneous bubble flow and turbulent flow regime was expressed by Eq. (7). However, more research is needed to clarify the boundary between the homogeneous bubble flow regime and the heterogeneous bubble flow and turbulent flow regime. 


\section{Acknowledgment}

This work was supported by a Grant-in-Aid for Energy Research (No. 60040005) from the Ministry of Education, Science and Culture of Japan.

\section{Nomenclature}

$C$

$=$ local concentration of solid particles in slurry

$C_{0} \quad=C$ extrapolated to $z=0$

$C_{L} \quad=C$ extrapolated to $z=L$

$C^{*} \quad=C$ in feed

$\bar{C} \quad=C$ averaged in column

$D_{T} \quad=$ column diameter

$d_{N} \quad=$ nozzle diameter

$d_{p} \quad=$ mean particle diameter

$E_{l} \quad=$ longitudinal dispersion coefficient of liquid

$E_{p} \quad=$ longitudinal dispersion coefficient of solid particles

$E_{s l} \quad=$ longitudinal dispersion coefficient of liquid in slurry

$L \quad=$ column height

$R e_{p} \quad=$ Reynolds number, $d_{p} v_{t} / v_{l}$

$U_{g} \quad=$ superficial velocity of primary gas

$U_{\mathfrak{g s}} \quad=$ superficial velocity of secondary gas

$U_{g t} \quad=U_{g}+U_{g s}$

$U_{l} \quad=$ superficial velocity of slurry

$=$ actual velocity of slurry, $U_{l} /\left(1-\varepsilon_{g}\right)$

$=$ mean settling velocity of solid particles

$=$ terminal velocity of solid particle

$=$ axial coordinate $\left[\mathrm{kg} \cdot \mathrm{m}^{-3}\right]$ $\left[\mathrm{kg} \cdot \mathrm{m}^{-3}\right]$ $\left[\mathrm{kg} \cdot \mathrm{m}^{-3}\right]$ $\left[\mathrm{kg} \cdot \mathrm{m}^{-3}\right]$ $\left[\mathrm{kg} \cdot \mathrm{m}^{-3}\right]$ [m] [m] [m]

$\left[\mathrm{m}^{2} \cdot \mathrm{s}^{-1}\right]$ $\left[\mathrm{m}^{2} \cdot \mathrm{s}^{-1}\right]$ id $\left[\mathrm{m}^{2} \cdot \mathrm{s}^{-1}\right]$ [m]

= exponent defined by Eq. (3)

= gas holdup

= gas holdup defined by Eq. (2)

$=$ liquid viscosity $v_{l} \quad=$ kinematic liquid viscosity

$\left[\mathrm{m}^{2} \cdot \mathrm{s}^{-1}\right]$

$\psi_{l} \quad=$ liquid fraction in slurry

$[-]$

\section{Literature Cited}

1) Aoyama, Y., K. Ogushi, K. Koide and H. Kubota: J. Chem. Eng. Japan, 1, 158 (1968).

2) Idogawa, K., M. Ikeda, T. Fukuda and S. Morooka: Kagaku Kogaku Ronbunshu, 12, 107 (1986).

3) Kara, S., B. G. Kelkar, Y. T. Shah and N. L. Carr: Ind. Eng. Chem. Process Des. Dev., 21, 584 (1982).

4) Kato, Y.: Kagaku Kōgaku, 27, 887 (1963).

5) Kato, Y., S. Morooka, T. Kago, T. Saruwatari and S.-Z. Yang: J. Chem. Eng. Japan, 18, 308 (1985).

6) Kato, Y. and A. Nishiwaki: Kagaku Kögaku, 35, 912 (1971); Int. Chem. Eng., 12, 182 (1972).

7) Kato, Y., A. Nishiwaki, T. Fukuda and S. Tanaka: I. Chem. Eng. Japan, 5, 112 (1972).

8) Kürten, H.: Chem.-Ing.-Tech, 54, 409 (1982).

9) Mochida, N.: ' 85 Int. Chem. Plant Eng. Exhib. Conf., Tokyo (1985).

10) Morooka, S., Y. Kạto, S. Ikejiri, M. Nakajima and $H$. Matsuyama: J. Chem. Eng. Japan, 19, 137 (1986).

11) Panvelkar, S. V., J. W. Tierney and Y. T. Shah: Chem. Eng. Sci., 37, 1582 (1982).

12) Pittsburg \& Midway Coal Mining Co.: DOE PC/50046-9 (1984).

13) Sangnimnuan, A., G. N. Prasad and J. B. Agnew: Chem. Eng. Commun., 25, 193 (1984).

14) Schügerl, K., J. Lücke and U. Oels: Adv. Biochem. Eng., 7, 1 (1977).

15) Smith, D. N. and J. A. Ruether: Chem. Eng. Sci, 40, 741 (1985).

16) Tarmy, B., M. Chang, C. Coulaloglou and P. Ponzi: Chem. Engr., Oct., 18 (1984).

17) Ying, D. H. S., R. Sivasubramanian, S. F. Moujaes and E. N. Givens: DOE ET/14801-30 (1982). 